\title{
The satisfaction with life scale: Psychometric properties in Pakistani population
}

\author{
Nadia Barki ${ }^{1}$, Fahad Riaz Choudhry², Khadeeja Munawar*3 (D) \\ Received: 14 Feb 2020 \\ Published: 25 Nov 2020
}

Abstract

Background: The construct of satisfaction with life has been studied across various cultures through the Satisfaction with Life Scale. The Satisfaction with Life Scale (SWLS) has been validated across several populations and languages. There are no published psychometric properties of its Urdu version. Hence, the aim of this study was to ascertain the psychometric properties of the Urdu version of the SWLS among the Urdu speaking population of Pakistan.

Methods: The SWLS has already been translated into Urdu, and the Urdu version is available on the author's website however there is no information about its psychometric properties. To establish the psychometric properties especially the factor structure of the already translated Urdu SWLS, the SWLS-Urdu was administered to Urdu speaking population residing in Pakistan. The statistical analyses (i.e., normality through skewness and kurtosis, Kaiser-Meyer-Olkin (KMO) and Bartlett's test of sphericity, and test and re-test reliability) were conducted through SPSS version 25.0. Structure Equation Modelling via maximum likelihood method of estimation was used to perform confirmatory factor analysis on the data using AMOS 20.0. The significance level was set at $\mathrm{p}<0.05$.

Results: The study was completed by recruiting 120 participants from different universities in Lahore, Pakistan. The sample was equally divided between male and female participants. The mean age of participants was 22.7(3.6) years. Test of the adequacy of the sample through Kaiser-Mayer-Olkin showed $\mathrm{KMO}=0.88$ and Bartlett's test of sphericity $(\mathrm{p}<0.001)$. The Cronbach's alpha reliability of the scale was 0.90 and Confirmatory Factor Analysis confirmed a one-factor model as a good fit with strong statistical evidence. No factorial group variances were noticed in male and female participants.

Conclusion: This study shows that Urdu SWLS has sound psychometric properties, is linguistically and culturally acceptable, and equally useful in assessing satisfaction with life in the Urdu speaking population.

Keywords: Life satisfaction, Well-being, University students, Exploratory factor analysis, Confirmatory factor analysis, Psychometrics

Conflicts of Interest: None declared

Funding: None

*This work has been published under CC BY-NC-SA 1.0 license.

Copyright $@$ Iran University of Medical Sciences

Cite this article as: Barki N, Choudhry FR, Munawar Kh. The satisfaction with life scale: Psychometric properties in Pakistani population. Med J Islam Repub Iran. 2020 (25 Nov);34:159. https://doi.org/10.47176/mjiri.34.159

\section{Introduction}

Satisfaction with life is an individual's present level of satisfaction with their past and present life. Diener, Emmons, Larsen, and Griffin (1985) and de Sousa, Santos, and

Corresponding author: Dr Khadeeja Munawar, khadeeja.munawar14@gmail.com

National Institute of Psychology, Quaid-i-Azam University, Islamabad, Pakistan

2. Department of Psychology, Kulliyyah of Islamic Revealed Knowledge and Human Sciences, International Islamic University Malaysia, Kuala Lumpur 53100, Malaysia

3. Department of Psychology, Jeffrey Cheah School of Medicine and Health Sciences, Monash University, Malaysia Bandar Sunway, Malaysia
Lopes et al. (2015) have given similar definitions of life satisfaction with the additional detail that life satisfaction is satisfaction according to the standard set by the individual

\section{$\uparrow$ What is "already known" in this topic:}

There are several scales that measure satisfaction with life, such as the Satisfaction with Life Scale (SWLS). The SWLS is a selfreport multiple-item questionnaire and it is widely used to measure life satisfaction among various populations. However, this is the first study to validate this instrument in the Urdu language to be used among Urdu speaking population.

$\rightarrow$ What this article adds:

The psychometric properties of the Urdu version of the Satisfaction with Life Scale (SWLS) were satisfactory. Thus, as a valid tool, it can be used for measuring satisfaction with life among Urdu speaking population. 
or based on their past experiences $(1,2)$. Nevertheless, life satisfaction is a subjective criterion and an individual's judgment of one's satisfaction depends on their own decision because according to Shin and Johnson (1978) life satisfaction is a process-based judgment and assessment of satisfaction is based on an individual criterion of satisfaction (3). Satisfaction with life holds significant value as it has been associated with other positive outcomes. According to past research, positive emotions lead to positive physiological outcomes which also include higher life expectancy (1). The previous research studies showed that satisfaction with life is related to longevity, gratitude and hope $(4,5)$. Hence, the factor of life satisfaction is important for immediate and long-term benefits.

There are several scales that measure satisfaction with life such as the Satisfaction with Life scale (SWLS). The SWLS is a self-report multiple-item questionnaire and it is widely used to measure life satisfaction among various populations (6). It was originally developed by Diener, Emmons, Larsen, and Griffin (1985) (2). It was suggested that satisfaction with life should be measured with a multiple item scale due to the subjective nature of satisfaction with life variable (7). Fortunately, SWLS fulfills this requirement, and it consists of five items to assess satisfaction with life.

The use of SWLS carries several advantages. Many researchers have determined the single factor of this scale through confirmatory factor analysis (8). On the contrary, there is limited evidence that the SWLS might not strictly adhere to a one-factor structure and a possibility of other dimensions may emerge (9). But such a possibility is limited in nature as other dimensions are minor in nature and do not affect the interpretation of the SWLS in terms of the total score on the scale (9). Nevertheless, to support the argument of a one-factor structure, many studies have established the unidimensionality of the scale. For example, the single-factor structure for the SWLS in the adolescent Portuguese sample has been reported (10). Similarly, a singlefactor of the SWLS has also been reported after testing it across Austria, Croatia, Serbia, Bosnia and Herzegovina, and Montenegro (9). Hence, the one-factor model of the SWLS has been confirmed across varying populations and demographic groups which hints at its extensive utilization and application.

The extensive use of the SWLS motivated this study, and the objective is to confirm the factor structure of the Urdu version of SWLS in Pakistani culture by administering it to the Pakistani sample of students. Confirmation of factor structure in the Urdu-speaking population is important due to the large size of this population in the world. Moreover, Pakistan's population is 207.8 million as of 2017 and the majority of this population speaks and understands Urdu $(11,12)$. However, the SWLS studies conducted in Pakistan do not provide information on the psychometric properties of the Urdu version of the SWLS. Therefore, it is important to establish the factor structure of the Urdu-version of the SWLS in the rapidly growing Urdu-speaking population of Pakistan.

\section{Methods}

This study was designed to confirm the factor structure of the SWLS Urdu version in the Urdu-speaking population and group variance between male and female demographics of the study. The study was conducted in Lahore which is an educational, industrial, and multicultural hub of Pakistan.

\section{Sample}

Lai, Chung, Lee, Kong Lok (2013) have suggested a 1:10 ratio to determine sample size in validation studies. Choudhry, Al-Worafi, Akram, Ahmed et al. (2018) have also used this method in their validation study to establish the factor structure of the Urdu version of the Flourishing Scale (12). Based on the method of 10 participants for every single item, the minimum sample size for this study was calculated to be 50 . However, 120 participants were included in this study in both of the test and retest phases. Hence, a convenience sample of 120 students participated in the study (Table 1). Data was collected from three private universities in different geographical areas of Lahore. The sample was approached on the basis of convenience and the questionnaire was filled on the spot. The sample included 60 males $(50 \%)$ and 60 females $(50 \%)$ whose age ranged between 17 to 28 years (Mean $\left.{ }_{\text {age }}=22.7, \mathrm{SD}=3.6\right)$. The majority $(\mathrm{N}=100 ; 83.33 \%)$ of the participants were residing in a dormitory and the rest of them were residing with their families.

\section{Instrument}

The Urdu version of the Satisfaction with Life Scale (SWLS) was employed in this study (2). The SWLS has already been translated in another study, and it is available on the authors' website (http://labs.psychology.illinois. edu/ ediener/SWLS.html); however; its psychometric properties have not been established. There is no further information about the Urdu version of the SWLS, its reliability, validity or the publication in which it had been translated. Hayat, Khan, and Sadia (2016) have used the Urdu version of the SWLS but the Urdu version used in their study was obtained from an unpublished dissertation (13). There is no further information about the SWLS Urdu version that can be accessed. This also indicates the need to establish the psychometric properties of the SWLS Urdu version. The SWLS Urdu version (SWLS-U) consists of 5 items with no negative items. The response on the scale is obtained on a 1 to 7 -point Likert scale. The scale ranges from strongly disagree to strongly agree (1 strongly disagree, 2 disagree, 3 slightly disagree, 4 neither disagree nor agree, 5 slightly agree, 6 agree, and 7 strongly agree). The total score for the scale ranges from 5 to 35 . A lower score indicates a lower level of satisfaction with life, while a high score indicates a higher level of satisfaction with life. On the original SWLS, the $\alpha$ reliability is reported to be 0.87 (2).

\section{Statistical Analysis}

The statistical analyses were conducted through SPSS version 25.0 and AMOS version 20.0. Before establishing 


\begin{tabular}{|c|c|c|}
\hline Characteristic & Frequency & $\%$ \\
\hline \multicolumn{3}{|l|}{ Gender } \\
\hline Male & 60 & $50 \%$ \\
\hline Female & 60 & $50 \%$ \\
\hline Other & 0 & 0.00 \\
\hline \multicolumn{3}{|l|}{ Family system } \\
\hline Joint & 62 & $51.7 \%$ \\
\hline Nuclear & 58 & $48.3 \%$ \\
\hline \multicolumn{3}{|l|}{ Residence } \\
\hline Dormitory & 100 & $83.3 \%$ \\
\hline With family & 20 & $16.6 \%$ \\
\hline \multicolumn{3}{|l|}{ Education } \\
\hline Intermediate (12 years of education) & 32 & $26.7 \%$ \\
\hline Graduation (14 years of education) & 31 & $25.8 \%$ \\
\hline Masters (16 years of education) & 38 & $31.7 \%$ \\
\hline MPhil (18 years of education) & 19 & $15.8 \%$ \\
\hline \multicolumn{3}{|l|}{ Perceived Socioeconomic status } \\
\hline Low & 14 & $11.7 \%$ \\
\hline Lower-middle & 15 & $12.5 \%$ \\
\hline Middle & 29 & $24.2 \%$ \\
\hline Middle-high & 41 & $34.2 \%$ \\
\hline High & 21 & $17.5 \%$ \\
\hline \multicolumn{3}{|l|}{ Age } \\
\hline IQR & \multicolumn{2}{|c|}{$7.00(19.0-26.0)$} \\
\hline Mean & \multicolumn{2}{|c|}{22.7} \\
\hline SD & \multicolumn{2}{|c|}{3.6} \\
\hline
\end{tabular}

test and re-test reliability, the data were checked for normality through the skewness and kurtosis method and was found to be normal. The $\alpha$ reliability of the scale was established through Cronbach's alpha reliability test. Additionally, detailed psychometric properties including mean, standard deviation, corrected total item correlation for each item of the scale, have also been computed.

To assess the sample for adequacy, Kaiser-Meyer-Olkin (KMO), and Bartlett's test of sphericity were conducted and showed good adequacy of the sample. The cut-off value for 'unacceptable' KMO is below 0.5 (14), values that lie in the range $0.5-0.7$ are considered "mediocre"; values in the range of 0.7 to 0.8 are "good"; "great" values fall in the range of 0.8 to 0.9 , and values lying above 0.9 are "superb" values (15).

Structure Equation Modelling via maximum likelihood method of estimation was used to perform confirmatory factor analysis on the data using AMOS 20.0. Confirmatory factor analysis indices showed an overall "good fit". It should be noted that the data was in the form of a Likert scale and was treated as a continuous variable. Many researchers (16-18) agree that a Likert variable with five and/or more categories can be treated as a continuous variable without having any adverse impact on the type of the analysis used; this should also explain the use of maximum likelihood estimation in CFA. Group variance was also computed for SWLS-U and the results showed no significant variance across groups.

\section{Results}

\section{Reliability}

Before conducting reliability analysis, the data were checked for normality through skewness and kurtosis. Skewness and kurtosis results show values ranging from -2 to +2 which indicate normalcy of the data. George and Mallery (2010) have given -2-+2 as an ideal range to prove the normality of the data (19). The SWLS-U showed a corrected inter-item correlation $\left(r_{\text {cit }} \geq 0.68\right)$ which increases the confidence in alpha reliability of the scale computed to be $\alpha=0.90$ (Table 2).

\section{Factor Structure of SWLS Urdu version}

Similar to the tradition of previous studies about psychometric properties of Satisfaction with Life Scale, this study confirmed the single-factor model of SWLS through confirmatory factor analysis among the Urdu-speaking population.

\section{Tests of Adequacy of Sample}

Kaiser-Meyer-Olkin test was used to verify the adequacy of the sample, which showed that the sample was adequate for this analysis, $\mathrm{KMO}=.88$. Moreover, Bartlett's test of sphericity was significant $\left(\chi^{2}(10)=415.38, p=0.000\right)$ which indicated the adequacy of the data.

\section{Confirmatory Factor Analysis (CFA)}

CFA was calculated through AMOS v20. The data from the retest dataset was analyzed through confirmatory factor analysis. CFA goodness of fit model was determined through $\chi^{2}$, Comparative Fit Index (CFI), Root Mean Square Error (RMSEA), and $\mathrm{p}$ of Close Fit (PCLOSE). Some additional indices (Table 3 ) have also been reported. The cut-off criteria for CFI are determined as $>.90$ (20); CFI value over .90 gives an acceptable fit $(21,22) \cdot \chi^{2}$ cutoff value varies from 5.0 to $2.0(14,23)$ and for RMSEA, the cut-off value range is from or lower than 0.06 to 0.08 (24). RMSEA can be especially brutal when the model is small with considerably fewer variables; it also casts doubt on the universal applicability of a single RMSEA threshold 
Table 2. Psychometric Properties of SWLS-Urdu (N=120)

\begin{tabular}{|c|c|c|c|c|c|c|}
\hline Scale/ Item & M & SD & $\mathrm{K}_{\mathrm{u}}$ & $\mathrm{S}_{\mathrm{k}}$ & $\mathrm{r}_{\mathrm{cit}}$ & $\alpha$ \\
\hline SWLS-U scale statistics & 11.9 & 5.74 & .31 & 1.04 & - & 0.90 \\
\hline 1. In most ways, my life is close to my ideal & 2.23 & 1.34 & 1.07 & 1.22 & 0.78 & - \\
\hline 2. The conditions of my life are excellent. & 2.35 & 1.24 & 0.69 & 1.08 & 0.77 & - \\
\hline 3. I am satisfied with my life. & 2.46 & 1.38 & 0.66 & 1.06 & 0.80 & - \\
\hline 4. So far, I have gotten the important things I want in my life & 2.38 & 1.29 & 0.31 & 0.96 & 0.75 & - \\
\hline 5. If I could live my life over, I would change almost nothing & 2.55 & 1.48 & -0.11 & 0.84 & 0.68 & - \\
\hline
\end{tabular}

5. If I could live my life over, I would change almost nothing

$\begin{array}{rrr}2.55 & 1.48 & -0.11\end{array}$

Table 3. Fit Indices to Establish Goodness-of-Fit, and Between-Groups Factorial Invariance

\begin{tabular}{lcccc}
\hline Sample & RMSEA & CFI & TLI & NFI \\
\hline Total $(\mathrm{N}=120)$ & 0.07 & 0.98 & 0.97 & 0.95 \\
Groups & & & 0.96 \\
Men and Women & 0.1 & 0.96 & 0.93 & 0.94 \\
Men & 0.11 & 0.97 & 0.95 & 0.94 \\
Women & 0.17 & 0.95 & 0.91 & 0.93 \\
\hline RMSEA = Root Mean Square Error of Approximation; CFI = Comparative Fit Index; TLI = Tucker Lewis Index; GFI = Goodness of fit Index; NFI = Normed Fit Index
\end{tabular}

RMSEA = Root Mean Square Error of Approximation; CFI = Comparative Fit Index; TLI = Tucker Lewis Index; GFI = Goodness of fit Index; NFI = Normed Fit Index

(25). Marsh et al. (2004) argue that recommended statistics for assessment of model fit are overly restrictive; they are merely guidelines and should not be strictly followed as golden rules (26). Nevertheless, the above stated fit indices were used only as reference in this study for CFA interpretation.

The retest data for Satisfaction with Life Scale was used for CFA, and all items were included in model testing. The single-factor model of the Urdu version of the SWLS was calculated to be a good fit in the Pakistani sample and Figure 1 shows the factor loadings.

CFA analysis showed the model as good fit as indicated by these indices: $\mathrm{CFI}=0.98$, RMSEA $=0.07$, TLI $=0.97$, and IFI $=0.98 . \chi^{2}$ was found to be insignificant at 0.126 level. The CFA indicates that the original single-factor model was accepted without any modifications.

CFA was also employed to determine group invariance across the factor 'life satisfaction'. Invariance was checked across the demographic 'gender'. Only two groups - men and women - were specified in the CFA datafile as 0 number of respondents had identified their gender as 'other'.

\section{Discussion}

SWLS has been extensively tested, and its psychometric properties have been established among several population groups. For example, the SWLS was administered on the Arabic speaking population and reliability of $\alpha=0.79$ was computed among this population (29). Similarly, the psychometric properties of the SWLS among a Brazilian sample have been established, and a single factor structure of the SWLS was confirmed with ample internal consistency (1). Another study tested the SWLS in the Mexican population and showed an internal reliability of $\alpha=0.74$ (30). Similarly, an internally consistent one-factor German version of the SWLS has also been established on a large German sample (31). The Satisfaction with Life Scale has also been administered to a sample of Spanish adolescents in an elaborate study to determine longitudinal invariance which showed nonsignificant age, gender, and longitudinal variance (32). Additionally, researchers have used the SWLS on the Pakistani population and concluded that $30.5 \%$ of the population was satisfied with their lives (33). Similar findings were shown in another study (34). Similar to pre-

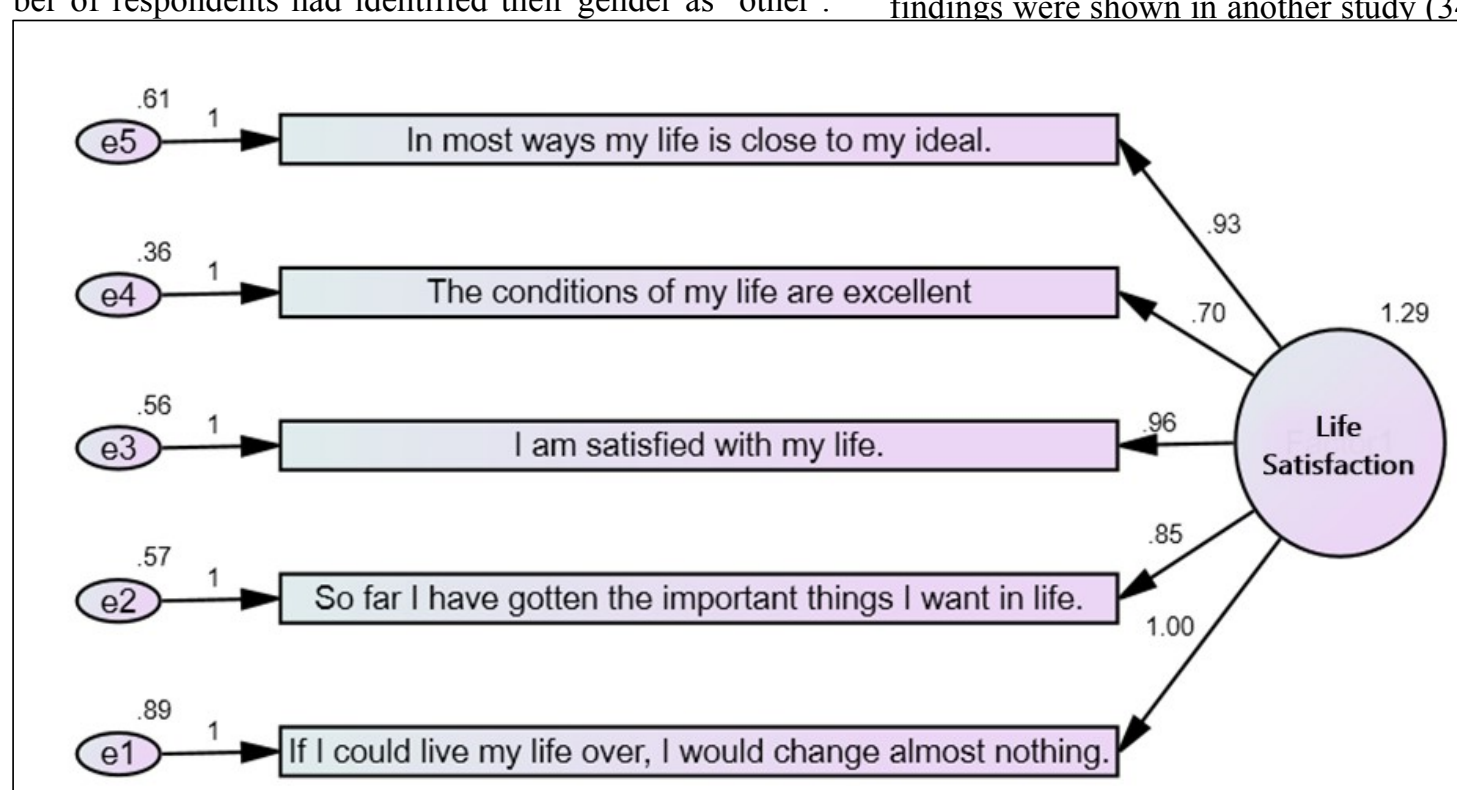

Fig 1. Single-factor Model of SWLS 
variation. Second, none of the participants were non-students; they all belonged to a similar walk of life. Last, most of the participants belonged to middle or higher socioeconomic status. Financial satisfaction can play a huge role in determining the life satisfaction of populations belonging to poor countries (35). Additionally, some studies (36) have also found that gender bears a significant impact on satisfaction with life through the measurement of various domains such as health and social support. It can be noted that in this study, the reported demographic factors combined to ensure some form of demographic homogeneity across the sample but the slight invariance across the current sample, even on a single demographic (gender), is noteworthy.

\section{Limitation and future direction}

The analysis shows ample evidence of good psychometric properties of the SWLS Urdu version in the Urdu speaking sample. It also briefly addresses the issues of normality and factorial invariance across groups. High inter-item correlation, strong reliability value, and a good-fit model support the use of the SWLS-U in future studies of life satisfaction in the Urdu-speaking population. However, despite the strong statistical evidence presented in this study, a limitation of age diversity remains. Future research using the Urdu version of the SWLS should be carried out with a diverse age range and a larger sample. Another future direction for the SWLS-U psychometric properties can be to compute invariances across other demographic characteristics such as age, level of income and education.

\section{Conclusion}

The analysis shows ample evidence of good psychometric properties of the SWLS Urdu version in the Urdu speaking sample. The statistical evidence shows that the SWLSUrdu can be used in future research studies in Pakistan and also in other Urdu speaking populations.

\section{Compliance with Ethical Standards}

This study was approved by the ethics committee of the National Institute of Psychology, Quaid-i-Azam University, Pakistan. The written informed consent was obtained from the participants of this study. Participants were ensured of the confidentiality of the data and anonymity of their identity.

\section{Conflict of Interests}

The authors declare that they have no competing interests.

\section{References}

1.de Sousa EMP, Santos WS, Lopes GS, da Costa TM, Cristino ED. Satisfaction with Life Scale: Evidence of Validity and Reliability in the Brazilian Context. Soc Inquiry Into Well. 2015;2(2):41-50.

2. Diener E, Emmons RA, Larsen RJ, Griffin S. The Satisfaction With Life Scale. J Pers Assess. 1985;49(1):71-5.

3. Shin DC, Johnson DM. Avowed Happiness as an Overall Assessment of the Quality of Life. Soc Indic Res. 1978;5(4):475-92.

4. Proyer RT, Ruch W, Buschor C. Testing Strengths-Based Interventions: A Preliminary Study on the Effectiveness of a Program Targeting Curiosity, Gratitude, Hope, Humor, and Zest for Enhancing Life Satisfaction. J Happiness Stud. 2013;14(1):275-92.

5. Diener E, Chan M. Happy People Live Longer: Subjective Well-Being
Contributes to Health and Longevity. Appl Psychol Health Well Being. 2011;3(1):1-43

6. Pavot W, Diener E. The satisfaction with life scale and the emerging construct of life satisfaction. J Posit Psychol. 2008;3(2):137-52.

7. Pavot W, Diener E, Suh E. The Temporal Satisfaction With Life Scale. J Pers Assess. 1998;70(2):340-54.

8. Durak M, Senol-Durak E, Gencoz T. Psychometric Properties of the Satisfaction with Life Scale among Turkish University Students, Correctional Officers, and Elderly Adults. Soc Indic Res. 2010;99(3):413-29.

9. Jovanović V, Brdar I. The cross-national measurement invariance of the Satisfaction with Life Scale in a sample of undergraduate students. Pers Individ Dif. 2018;128:7-9.

10. Neto F. The satisfaction with life scale: Psychometrics properties in an adolescent sample. J Youth Adolesc. 1993;22(2):125-34.

11. Dawn. Pakistan's population has ballooned to $207.8 \mathrm{~m}$, provisional census results show. Dawn. 2017.

12. Choudhry FR, Al-Worafi YM, Akram B, Ahmed MA, Anwar Ul Haq M, Khan TM, et al. Factor Structure of Urdu Version of the Flourishing Scale. Front Psychol. 2018;9:1513-

13. Hayat SZ, Khan S, Sadia R. Resilience, wisdom, and life satisfaction in elderly living with families and in old-age homes. PJPR. 2016;31(2).

14. Wheaton B, Muthen B, Alwin DF, Summers GF, editors. Assessing reliability and stability in panel models. San Francisco: Jossey-Bass. 1977

15. Hoyle RH. Confirmatory factor analysis. Handbook of applied multivariate statistics and mathematical modeling: Elsevier; 2000. p. 465-97.

16. Li CH. Confirmatory factor analysis with ordinal data: Comparing robust maximum likelihood and diagonally weighted least squares. Behav Res Methods. 2016;48(3):936-49.

17. Flora DB, Curran PJ. An empirical evaluation of alternative methods of estimation for confirmatory factor analysis with ordinal data. Psychol Methods. 2004;9(4):466-91.

18. Lei P-W, Shiverdecker LK. Performance of Estimators for Confirmatory Factor Analysis of Ordinal Variables with Missing Data Struct Equ Modeling. 2019:1-18.

19. George D. SPSS for windows step by step: A simple study guide and reference, 17.0 update, 10/e: Pearson Education India; 2011.

20. Browne MW, Cudeck R, editors. Alternative ways of assessing model fit Newbury Park: Sage Google Scholar; 1993.

21. Hooper D, Coughlan J, Mullen MR. Structural equation modelling: Guidelines for determining model fit. Electron J Bus Res Methods. 2008;6(1):53-60.

22. Bentler PM. On tests and indices for evaluating structural models. Pers Individ Dif. 2007;42(5):825-9.

23. Tabachnick BG. Using multivariate statistics. 5th ed. ed. Fidell LS, editor. Boston: Pearson/Allyn \& Bacon; 2007.

24. Schreiber JB, Nora A, Stage FK, Barlow EA, King J. Reporting Structural Equation Modeling and Confirmatory Factor Analysis Results: A Review. J Educ Res. 2006;99(6):323-38.

25. Chen F, Curran PJ, Bollen KA, Kirby J, Paxton P. An empirical evaluation of the use of fixed cutoff points in RMSEA test statistic in structural equation models. Soc Methods Res. 2008;36(4):462-94.

26. Marsh HW, Hau KT, Wen Z. In search of golden rules: Comment on hypothesis-testing approaches to setting cutoff values for fit indexes and dangers in overgeneralizing $\mathrm{Hu}$ and Bentler's (1999) findings. Struct Equ Model. 2004;11(3):320-41.

27. Kenny DA, Kaniskan B, McCoach DB. The Performance of RMSEA in Models With Small Degrees of Freedom. Soc Methods Res. 2014;44(3):486-507.

28. Schermelleh-Engel K, Moosbrugger H, Müller H. Evaluating the fit of structural equation models: Tests of significance and descriptive goodness-of-fit measures. Methods Psy Sci. 2003;8(2):23-74.

29. Abdallah T. The Satisfaction with Life Scale (SWLS): Psychometric Properties in an Arabic-speaking Sample. Int J Adolesc Youth. 1998;7(2):113-9.

30. López-Ortega M, Torres-Castro S, Rosas-Carrasco O. Psychometric properties of the Satisfaction with Life Scale (SWLS): secondary analysis of the Mexican Health and Aging Study. Health Qual Life Outcomes. 2016;14(1):170-

31. Glaesmer H, Grande G, Braehler E, Roth M. The German version of the satisfaction with life scale (SWLS). Eur J Psychol Assess. 2011.

32. Esnaola I, Benito M, Antonio-Agirre I, Axpe I, Lorenzo M. Longitudinal measurement invariance of the Satisfaction With Life 
Scale in adolescence. Qual Life Res. 2019:1-7.

33. Akram A, ul Haq N, Riaz S, Ahmed N, Hamid R. PIH64 - Satisfaction with life of general population of pakistan. A nation wide survey. Value Health. 2015;18(7):A743.

34. Munawar K, Tariq O. Exploring Relationship Between Spiritual Intelligence, Religiosityvariables and Life Satisfaction Among Elderly Pakistani Muslims. J Relig Health. 2018;57(3):781-95.

35. Xiao JJ, Tang C, Shim S. Acting for happiness: Financial behavior and life satisfaction of college students. Soc Indic Res. 2009;92(1):53-68.

36. Loewe N, Bagherzadeh M, Araya-Castillo L, Thieme C, BatistaFoguet JM. Life Domain Satisfactions as Predictors of Overall Life Satisfaction Among Workers: Evidence from Chile. Soc Indic Res. 2014;118(1):71-86. 